\title{
Performance Enhancement in PV System usingIntelligent Controller based MPPT Controller
}

\author{
G.Vinodhkumar \\ P.G Scholar, Jeppiaar Engineering College,Chennai, Tamilnadu, India. \\ Ms.V. Reena Joshi Vince \\ Assistant Professor, Jeppiaar Engineering College,Chennai, Tamilnadu, India. \\ ,Dr.M.Sasikumar \\ Professor, Jeppiaar Engineering College,Chennai, Tamilnadu, India.
}

\begin{abstract}
Photovoltaic energy has an increased importance in present day electrical power applications, because it is considered as an essentially inexhaustible and broadly available energy resource. However, the output power provided via the Photo Voltaic (PV) conversion process depends on solar irradiation and temperature. Therefore, to maximize the efficiency of the photovoltaic energy system, it is necessary to track the maximum power point of the PV array. This project proposes a Maximum Power Point Tracker (MPPT) method, based on Fuzzy Logic Controller (FLC), applied to a stand-alone photovoltaic system. It uses a sampling measure of the $P V$ array power and voltage to determine an increment required, to have the optimal operating voltage which permits Maximum Power Point Tracking. This method carries high accuracy around the optimum point when compared to the other conventional MPPT algorithms. The proposed system consists of a stand-alone PV system, DC/DC Boost converters and a load .Converter regulates voltage and current to provide a continuous maximum power to the load. The simulation results shows the effectiveness of the proposed fuzzy logic controller applied for the $P V$ system and the simulation is done by using MATLAB.
\end{abstract}

\section{Introduction}

Photovoltaic cells or panels are only one way of generating electricity from solar energy. They are not the most efficient, but they are the most convenient to use on a small to medium scale. PV cells are made of silicon, similar to that used in computer "chips". While silicon itself is a very abundant mineral, the manufacture of solar cells (as with computer chips) has to be in a very clean environment. This causes production costs to be high. The photovoltaic process is a technology in which radiant energy from the sun is converted to direct current (DC) electricity. The PV array has a unique operating point that can supply maximum power to the load. This point is called the maximum power point (MPP). The locus of this point has a non-linear variation with solar irradiation and the cell temperature. Efficient techniques requiredto track the maximum available output power of PV systems are called the MPPT.MPPT is an electronic system that operates the Photovoltaic (PV) modules in a manner that allows the modules to produce all the power they are capable of. MPPT is not a mechanical tracking system that "physically moves" the modules to make them point more directly at the sun. MPPT is a fully electronic system thatvaries the electrical operating point of the modules, so that the modules are able to deliver maximum available power. Additional power harvested from the modules is then made available as increased battery charge current. MPPT can be used in conjunction with a mechanical trackingsystem, but the two systems are completely different. When a conventional controller is charging a discharged battery, it simply connects the modules directly to the battery. This forces the modules to operate at battery voltage, typically not the ideal operating voltage at which the modules are able to produce their maximum available power. The PV Module Power/Voltage/Current graph (Figure1.1) shows the traditional Current/Voltage curve for a typical $75 \mathrm{~W}$ module at standard test conditions of $25^{\circ} \mathrm{C}$ cell temperature and $1000 \mathrm{~W} / \mathrm{m} 2$ of insolation.

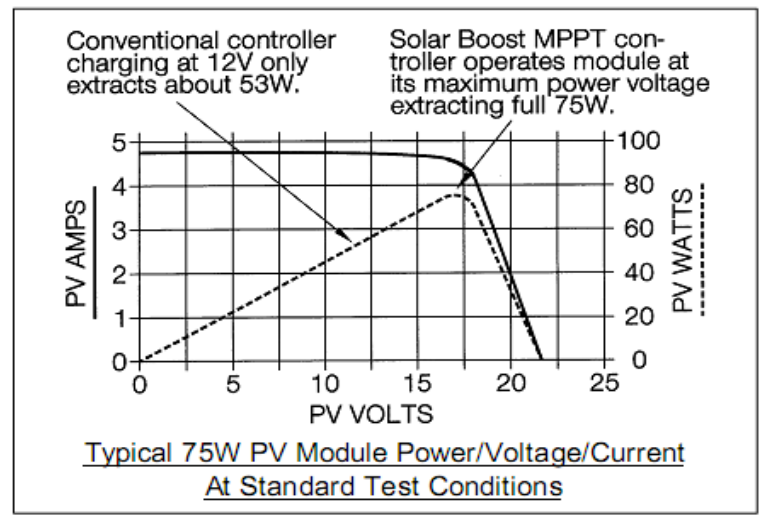

Figure 1.1 Power/voltage/current curve of a $75 \mathrm{w}$ PV panel. 


\section{G.Vinodhkumar, Ms.V. Reena Joshi Vince, Dr.M.Sasikumar / IOSR Journal of Engineering (IOSRJEN) www.iosrjen.org

Vol. 2 Issue 2, Feb.2012, pp. 284-287

This graph also shows PV module power delivered vs. module voltage. For the example shown, the conventional controller simply connects the module to the battery and therefore forces the module to operate at $12 \mathrm{~V}$. By forcing the $75 \mathrm{~W}$ module to operate at $12 \mathrm{~V}$ the conventional controller artificially limits power production to $\approx 53 \mathrm{~W}$. Rather than simply connecting the module to the battery, the patented MPPT system in a dc-dc converter calculates the voltage at which the module is able to produce maximum power.

\section{Photovoltaic Array System Modeling}

The equivalent circuit of the PV cell is shown in Fig 2.1.

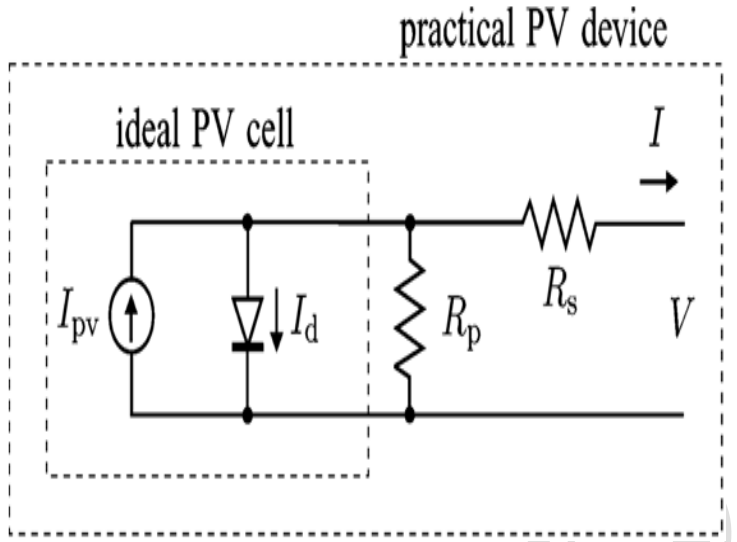

Fig 2.1 Equivalent Circuit of a PV Cell

Thebasic equation from the theory of semiconductors that mathematicallydescribes the $I-V$ characteristic of the ideal PV cellis

$I=I_{\text {pwicen }}-I_{d}$

Where,

$$
I_{d}=I_{0, \operatorname{cen}}\left[\exp \left(\frac{\mathrm{av}}{\mathrm{akT}}\right)-1\right]
$$

Therefore,

$I=I_{p v_{1}, \mathrm{cen}}-I_{0, \mathrm{cen}}\left[\exp \left(\frac{\mathrm{q} V}{\mathrm{akT}}\right)-1\right]$

where $\mathrm{I}_{\mathrm{pv}, \mathrm{cell}}$ is the current generated by the incident light (it is directly proportional to the Sun irradiation), Id is the Shockley diode equation, $\mathrm{I}_{0 \text {,cell }}$ is the reverse saturation or leakage current of the diode, $q$ is the electron charge $(1.60217646 \times 10-19 \mathrm{C}), k$ is the Boltzmann constant $(1.3806503 \times 10-23 \mathrm{~J} / \mathrm{K}), T$ (in Kelvin) is the temperature of the $p-n$ junction, and $a$ is the diode ideality constant.PV panel is modeled as an equivalent current source. The various equations describing the PV panel characteristics are modeled using suitable mathematical blocks from the MATLAB Simulink library. The circuit model of the PV panel is shown in figure. This simulation is done for standard test condition (STC) when temperature is $25^{\circ} \mathrm{C}$ and Irradiation is $1000 \mathrm{~W} / \mathrm{m}^{2}$.
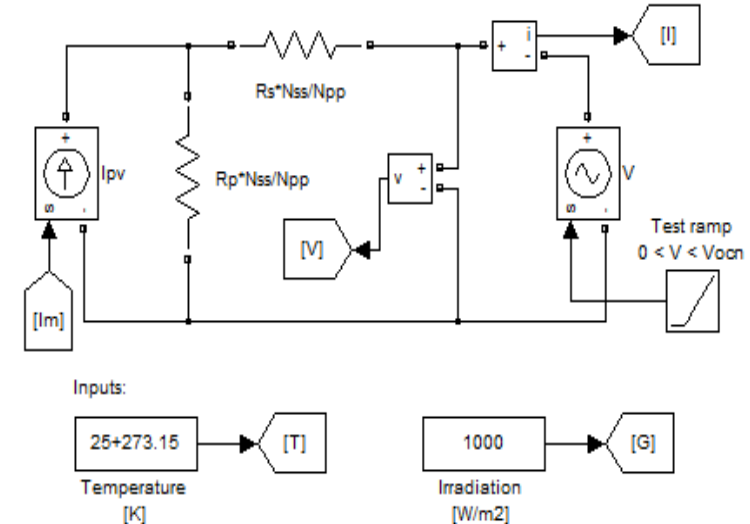

Fig 2.2 Equivalent circuit of solar PV using MATLAB

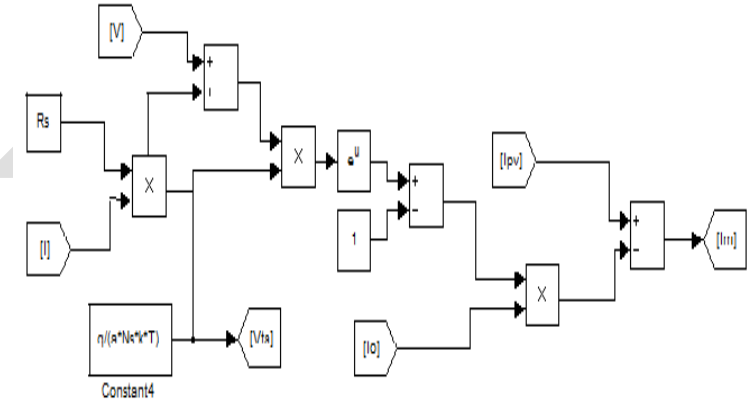

Fig 2.3 Maximum current (Im) of Solar PV using MATLAB

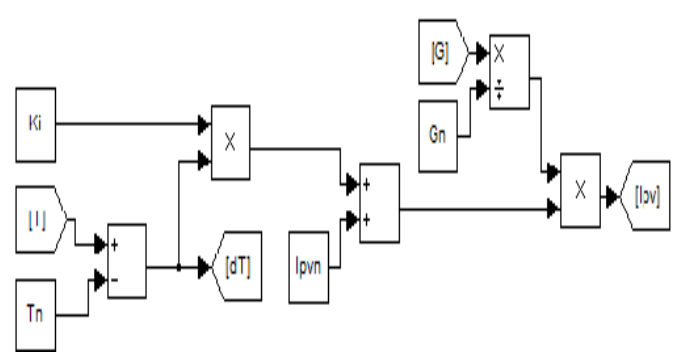

Fig 2.4 Current generated by the incident light (Ipv) of PV using MATLAB

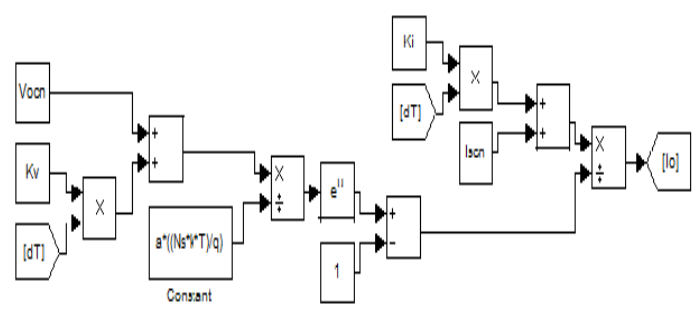

Fig 2.5 Reverse saturation current (Io)using MATLAB 


\section{G.Vinodhkumar, Ms.V. Reena Joshi Vince, Dr.M.Sasikumar / IOSR Journal of Engineering (IOSRJEN)

Vol. 2 Issue 2, Feb.2012, pp. 284-287

\subsection{Parameters of the PV panel-Tata BP 1235}

\begin{tabular}{|l|l|}
\hline Open Circuit Voltage Voc & $38 \mathrm{~V}$ \\
\hline Short circuit Current Isc & $1.9 \mathrm{~A}$ \\
\hline Maximum Voltage Vm & $27.5 \mathrm{~V}$ \\
\hline Maximum Current Im & $1.35 \mathrm{~A}$ \\
\hline
\end{tabular}

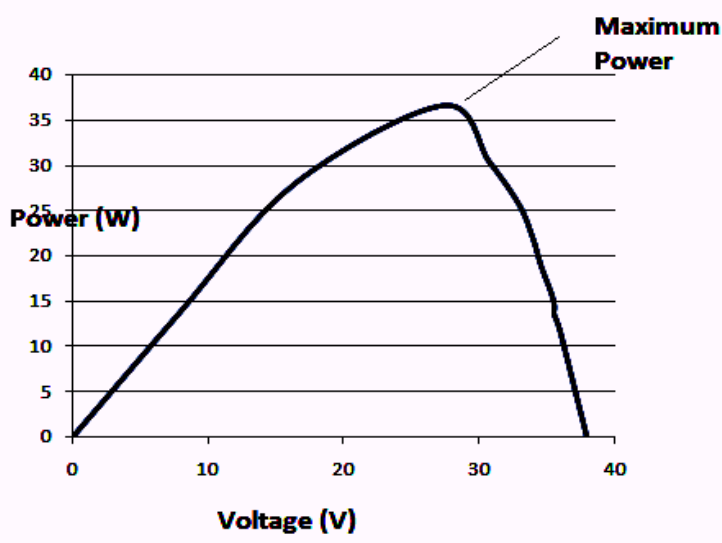

Fig 2.6 P-V Characteristics of a 36W Solar Panel

\section{Maximum Power Point Tracking Control and DC-DC Boost converter}

The role of the MPPT is to ensure the operation of the PV generator at its MPP, extracting the maximum available power. However, their losses have to be small enough to improve the efficiency of the overall system. This could increase the gap between the PV peak power voltage and the voltage at which they are forced to operate in a system without a peak power tracking. Theoretically, it is foreseeable that a MPPT would yield the most impressive gains in cold weather because that would raise the PV array' peak power voltage point well above the usual battery operating voltage. Fig. 6 shows the general block diagram for a charge batteries system, with MPPT, using a generic DC/DC converter.This one is connected to the PV generator, a battery and a load profile (such as a resistance, DC/DC motor).[4] The main objective is to obtain the maximum power from the PV generator for the first load batteries stage. That is to say, when the batteries are fully or partially discharged, in some state of charge less than $100 \%$, then it is necessary to control one/or some of the input/output following variables.

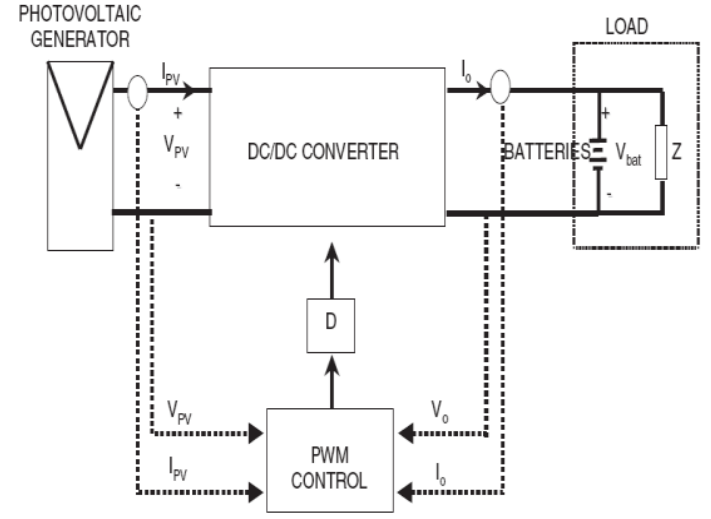

Fig 3.1 Block diagram of solar panel with MPPT The main components in fuzzy logic based MPPT controller are fuzzification, rule-base, and inference and defuzzification as shown in Fig. 3.2.[4] The input variables to the controller are the change in PV array power $(\Delta \mathrm{Ppv})$ and change in voltage $(\Delta \mathrm{Vpv})$ whereas the output of the controller is the step change of boost converter Voltage reference ( $\Delta$ Vref). This is used to drive the boost converter to maximize the output from solar PV panel.

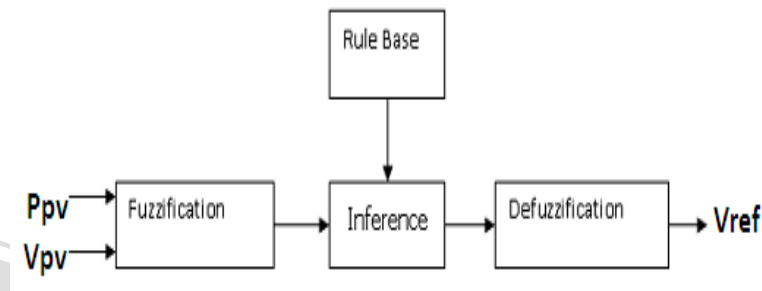

The proposed FLC measures the PV array characteristics and then perturbs the operating voltage by an optimal increment $(\Delta \mathrm{Vpv}, \mathrm{ref})$ and the resulting $\mathrm{PV}$ power change.[5] The power variation $(\Delta \mathrm{Ppv})$ is either in the positive direction or in the negative one. The value of $(\Delta \mathrm{Ppv})$ can also be small or large. From these judgments, the reference photovoltaic voltage variation $(\Delta \mathrm{Vpv}, \mathrm{ref})$ is increased or decreased in a small or respectively large way in the direction which makes it possible to increase the power Ppv. The control rules are indicated in Table 3.1 with $(\Delta \mathrm{Ppv})$ and $(\Delta \mathrm{Vpv})$ as inputs, while $(\Delta \mathrm{Vpv}, \mathrm{ref})$ represents the output. These inputs and output variables are expressed in terms of linguistic variables (such as BN (big negative), MN (means negative), SN (small negative), Z (zero), SP (small positive), MP (means positive), and BP (big positive)). From these linguistic rules, the FLC proposes a variation of the reference voltage $\Delta \mathrm{V}$ according to Eqs. (3.1-3.2).wherePpv[k] and $\mathrm{Vpv}[\mathrm{k}]$ are the power and voltage of the photovoltaic generator at sampled times $(\mathrm{k})$, and Vpv,ref[k] the instant of reference voltage.[2] 


\section{G.Vinodhkumar, Ms.V. Reena Joshi Vince, Dr.M.Sasikumar / IOSR Journal of Engineering (IOSRJEN) Www.iosrjen.org

Vol. 2 Issue 2, Feb.2012, pp. 284-287

Table 3.1 FUZZY RULE TABLE

\begin{tabular}{|l|l|l|l|l|l|}
\hline$\Delta \mathbf{V p v} \backslash \mathbf{P p v}$ & NB & NS & $\mathbf{Z}$ & PS & PB \\
\hline NB & NB & NB & NB & NS & Z \\
\hline NS & NS & NS & NS & Z & Z \\
\hline Z & Z & Z & Z & PS & PS \\
\hline PS & Z & Z & PS & PS & PS \\
\hline PB & Z & PS & PB & PB & PB \\
\hline
\end{tabular}

$$
\begin{aligned}
& \mathrm{P}_{\mathrm{pv}}^{\mathrm{k}}=\mathrm{V}_{\mathrm{pv}}^{\mathrm{k}} * \mathrm{I}_{\mathrm{pv}}^{\mathrm{k}} \\
& \Delta \mathrm{P}_{\mathrm{pv}}^{\mathrm{k}}=\mathrm{P}_{\mathrm{pv}}^{\mathrm{k}}-\mathrm{P}^{\mathrm{k}-1}{ }_{\mathrm{pv}} \\
& \Delta \mathrm{V}_{\mathrm{pv}}^{\mathrm{k}}=\mathrm{V}_{\mathrm{pv}^{-}}^{\mathrm{k}} \mathrm{V}^{\mathrm{k}-1}{ }_{\mathrm{pv}}
\end{aligned}
$$

\section{Simulation Results}

The input to the controller is voltage and power signals from the PV panels which are analog signals. The output from the controller is PWM pulses of varying duty cycles. This fuzzy logic based controller is connected with solar PV panel as a closed loop system. This closed loop system is maximize the solar panel PV power output.

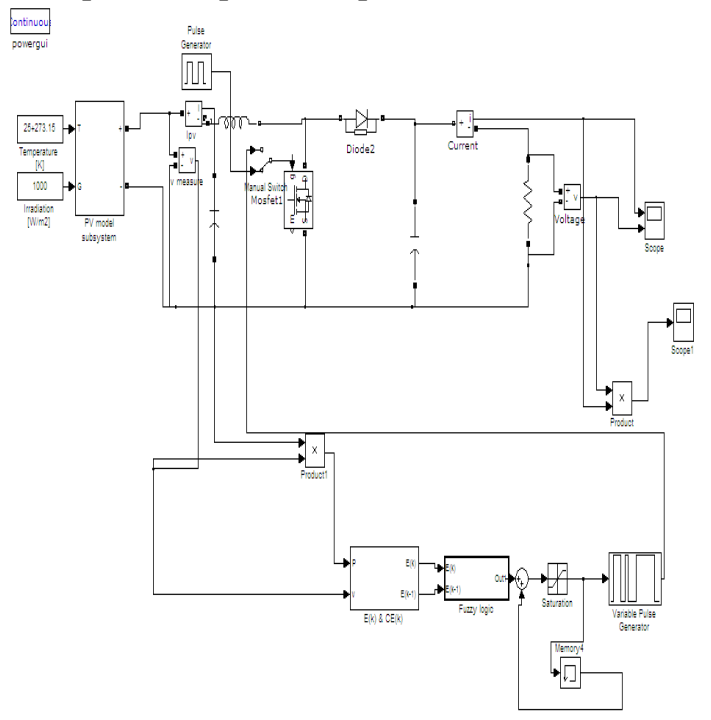

Fig 4.1 Integrated PV Panel with Fuzzy based MPPT Controller using MATLAB

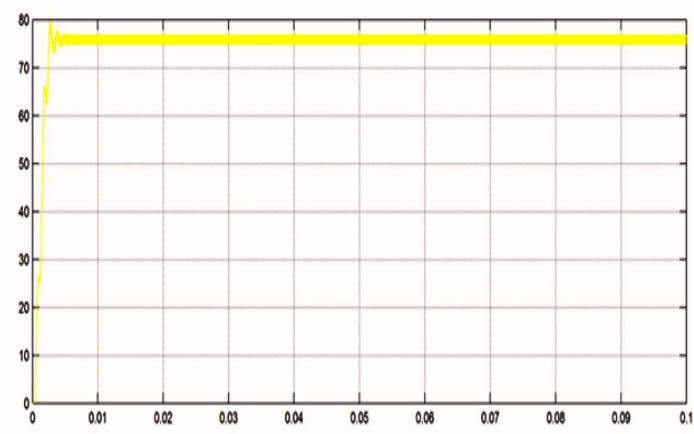

Fig 4.2 MATLAB simulated Maximum Power Ouput with Fuzzy based MPPT controller

\section{Conclusion}

In order to improve the efficiency of PV systems, under different temperature and irradiance conditions, intelligent control techniques for the tracking of the maximum power point were investigated in this paper. The design and simulation of a fuzzy logic based MPPT controller was proposed using MATLAB. They achieved very good performances, fast responses with no overshoot and less fluctuations in the steady state, for rapid irradiance and temperature variations. This means that these controllers are able to maintain very rapidly the operating point of the PV systems at the maximum power point hence improving the amount of energy effectively extracted from the PV modules, i.e. increasing the efficiency of the PV system.

\section{References}

1. H.D. Maheshappa, J. Nagaraju and M. V. Murthy, An improved maximum power point tracker using a step-up converter with current locked loop, Renewable Energy, vol. 13, n² 2, pp. 195-201, 1998.

2. Ch. Hua and Ch. Shen, Comparative study of peak power tracking techniques for solar storage system, in IEEE Applied Power Electronics Conference and Exposition (APEC'98), Vol. 2, 1998, pp. 679-685.

3. Z. Salameh and Daniel Taylor, Step-up maximum power point tracker for photovoltaic arrays, Solar Energy, Vol. 44, n 1, 1990, pp. 57-61.

4. Villalva M G "Modelling and circuitbasedsimulation of photovoltaic arrays", IEEE Transactions on Power Electronics, 2009 vol. 25, no. 5, pp. 1198-1208.

5. Ch. Hua and Ch. Shen, Comparative study of peak power tracking techniques for solar storage system, in IEEE Applied Power Electronics Conference and Exposition (APEC'98), Vol. 2, 1998, pp. 679-685.

6. Z. Salameh and Daniel Taylor, Step-up maximum power point tracker for photovoltaic arrays, Solar Energy, Vol. 44, n 1, 1990, pp. 57-61. 